\title{
Previously unrecognised division within Moritella viscosa isolated from fish farmed in the North Atlantic
}

\author{
S. Grove ${ }^{1}$, C. R. Wiik-Nielsen ${ }^{1}$, T. Lunder ${ }^{3,6}$, H. S. Tunsj ${ }^{2}$, N. M. Tandstad ${ }^{1}$, \\ L. J. Reitan ${ }^{1}$, A. Marthinussen ${ }^{4,7}$, M. Sørgaard ${ }^{1}$, A. B. Olsen ${ }^{5}$, D. J. Colquhoun ${ }^{1, *}$ \\ ${ }^{1}$ National Veterinary Institute, Oslo, PO Box 8156 Dep, 0033 Oslo, Norway \\ ${ }^{2}$ Norwegian School of Veterinary Science, PO Box 8146, 0033 Oslo, Norway \\ ${ }^{3}$ ScanVacc AS, PO Box 233, 2151 Årnes, Norway \\ ${ }^{4}$ Lerøy Hydrotech AS, Bentnesveien 50, 6512 Kristiansund, Norway \\ ${ }^{5}$ National Veterinary Institute, Bergen, PO Box 1263 Sentrum, 5811 Bergen, Norway \\ ${ }^{6}$ Present address: Novartis Aqua Norway, PO Box 237 Økern, Oslo, Norway \\ ${ }^{7}$ Present address: Aqua Gen AS, PO Box 1240, 7462 Trondheim, Norway
}

\begin{abstract}
Previously undocumented phenotypical and genetic variation was identified amongst isolates of Moritella viscosa collected from various geographical locations and from different fish species. The studied isolates could be split into 2 major phenotypically and genetically different clusters, one of which was consistent with the species type strain (NCIMB 13548). Isolates consistent with the type strain originated exclusively from Atlantic salmon farmed in Norway, Scotland and the Faroe Isles, although a single isolate from farmed Norwegian cod clustered closely with this group. The 'variant' cluster comprised isolates originating from Norwegian farmed rainbow trout, Icelandic farmed rainbow trout and salmon, Canadian farmed (Atlantic) salmon, Icelandic lumpsucker and only exceptionally from Norwegian salmon. With the exception of the single aforementioned cod isolate, all isolates from Norwegian farmed cod belonged to the variant cluster. Phenotypically, the clusters could be absolutely separated only by elevated haemolytic activity in the variant strain, although approximately half of these isolates also produced acid from mannose, in contrast to the typical (type) strain. While 16S rRNA gene sequencing was unable to separate the 2 clusters, Western blot analyses, plasmid profile analysis, pulsed field gel electrophoresis and gyrB gene sequence analysis produced clusters consistent with the phenotypic data. Macroscopically and histologically the disease in rainbow trout caused by the variant strain was consistent with that previously described in Atlantic salmon. The results of the present study may indicate a degree of host specificity of the typical strain for Atlantic salmon.
\end{abstract}

KEY WORDS: Rainbow trout · Atlantic salmon · Oncorhynchus mykiss · Salmo salar · Gadus morhua • Moritella viscosa $\cdot$ Cyclopterus lumpus $\cdot$ Winter-ulcer

\section{INTRODUCTION}

Moritella viscosa is believed to be the dominating aetiological agent of 'winter-ulcer' in Atlantic salmon Salmo salar and rainbow trout Oncorhynchus mykiss farmed in the Northern Atlantic area. Despite the widespread availability of commercial $M$. viscosa vaccines providing high levels of protection against experimental challenge, and increasing levels of field pro- tection, winter-ulcer continues to be the major bacteria-related loss in Norwegian salmonid farming.

Although first reported in Norway (Lunder 1992), the bacterium has also been isolated regularly from diseased farmed salmonids in Iceland (Benediktsdóttir et al. 1998) and less frequently in the Faroe Islands (Inger Dalsgaard pers. comm.), Scotland (Bruno et al. 1998) and Canada (Whitman et al. 2000). While Atlantic cod Gadus morhua have been shown to be experimentally 
susceptible to Moritella viscosa infection (Gudmundsdóttir et al. 2006) and the bacterium has also been isolated from farmed cod (Colquhoun et al. 2004), captive wild-caught plaice Pleuronectes platessa (Lunder et al. 2000) and lumpsucker Cyclopterus lumpus (Benediktsdóttir et al. 2000), it is not yet clear whether it can be considered a true disease agent in these species. In experimental challenges, turbot Scophthalmus maximus and, to a lesser degree, Atlantic halibut Hippoglossus hippoglossus have been shown to be susceptible to infection with $M$. viscosa (Björnsdóttir et al. 2004, Gudmundsdóttir et al. 2006).

A degree of geographically based amplified fragment length polymorphism (AFLP) clustering within Moritella viscosa isolates has been demonstrated (Benediktsdóttir et al. 2000) and the existence of 4 different serotypes was recently shown (Heidarsdóttir et al. 2008). However, until the present study the Norwegian $M$. viscosa population had been considered relatively homogeneous, an assumption probably based on lack of evidence to the contrary, rather than direct evidence of homogeneity.

The present study was initiated against a background of systemic Moritella viscosa infections in farmed rainbow trout in Norway which, in recent years, have occurred with irregular frequency but high virulence and associated mortalities. As M. viscosa isolated from these outbreaks appeared to differ slightly phenotypically from those normally isolated from Atlantic salmon in Norwegian waters, the present study was instigated to survey heterogeneity amongst Norwegian $M$. viscosa, with focus on both 'typical' isolates from salmon and the increasing yet still relatively small number of 'atypical' isolates archived from rainbow trout, cod and also exceptionally from Atlantic salmon. For comparative purposes, representative isolates from diverse geographical origins and host species were included.

\section{MATERIALS AND METHODS}

Bacterial isolates and maintenance. Norwegian isolates were collected as submissions to the clinical diagnostic bacteriology service provided by the National Veterinary Institute. Isolates from Canada, Iceland, Scotland and the Faroe Islands were kindly donated by various researchers (Table 1).

Phenotypical characterization. Cells from cultures grown for $48 \mathrm{~h}$ at $15^{\circ} \mathrm{C}$ on blood agar with $2 \% \mathrm{NaCl}$ (BAS) were used in all tests. Unless otherwise noted, the final $\mathrm{NaCl}$ content of test media was $2 \%$. The studied isolates were subjected to the standard (limited) range of phenotypical tests currently used in the identification of Moritella viscosa in our laboratory, comprising descrip-
Table 1. Bacterial strains in Salmo salar, Oncorhynchus mykiss, Gadus morhua and Cyclopterus lumpus. NVI: National Veterinary Institute, Norway; JCM: Japan Collection of Microorganisms; NCIMB: National Collection of Industrial Marine Bacteria

\begin{tabular}{|c|c|c|}
\hline $\begin{array}{l}\text { Strain } \\
\text { designation }\end{array}$ & $\begin{array}{l}\text { Species isolated } \\
\text { from }\end{array}$ & $\begin{array}{l}\text { Geographical } \\
\text { origin }\end{array}$ \\
\hline \multicolumn{3}{|l|}{ Moritella viscosa } \\
\hline NCIMB 13584 & S. salar & Norway \\
\hline NVI 2989 & S. salar & Norway \\
\hline NVI 6216 & S. salar & Norway \\
\hline NVI 1527 & S. salar & Norway \\
\hline NVI 4397 & S. salar & Norway \\
\hline NVI 5443 & S. salar & Norway \\
\hline NVI 6562 & S. salar & Norway \\
\hline NVI 4679 & S. salar & Norway \\
\hline NVI 3999 & S. salar & Norway \\
\hline NVI 4179 & S. salar & Norway \\
\hline NVI 4731 & S. salar & Norway \\
\hline NVI 5433 & S. salar & Norway \\
\hline LFI $5006^{a}$ & S. salar & Norway \\
\hline $990129-1 / 3 \mathrm{~B}^{\mathrm{b}}$ & S. salar & Faroe Islands \\
\hline $990217-1 / 1 \mathrm{~A}^{\mathrm{b}}$ & S. salar & Faroe Islands \\
\hline MT $2858^{c}$ & S. salar & Scotland \\
\hline MT $2528^{c}$ & S. salar & Scotland \\
\hline $\mathrm{K} 2^{\mathrm{d}}$ & S. salar & Iceland \\
\hline $\mathrm{K} 58^{\mathrm{d}}$ & S. salar & Iceland \\
\hline $\mathrm{F} 153^{\mathrm{d}}$ & S. salar & Iceland \\
\hline $\mathrm{K} 56^{\mathrm{d}}$ & S. salar & Iceland \\
\hline Vvi-7 & S. salar & Canada \\
\hline Vvi-11 & S. salar & Canada \\
\hline NVI 5168 & O. mykiss & Norway \\
\hline NVI 4917 & O. mykiss & Norway \\
\hline NVI 4692 & O. mykiss & Norway \\
\hline NVI 4958 & O. mykiss & Norway \\
\hline NVI 5450 & O. mykiss & Norway \\
\hline NVI 5683 & O. mykiss & Norway \\
\hline NVI 6185 & O. mykiss & Norway \\
\hline NVI 3968 & O. mykiss & Norway \\
\hline NVI 6184 & O. mykiss & Norway \\
\hline NVI 4869 & O. mykiss & Norway \\
\hline $\mathrm{F} 162 / 01^{\mathrm{d}}$ & O. mykiss & Iceland \\
\hline NVI 5471 & G. morhua & Norway \\
\hline NVI 5507 & G. morhua & Norway \\
\hline NVI 5204 & G. morhua & Norway \\
\hline NVI 4547 & G. morhua & Norway \\
\hline NVI 5482 & G. morhua & Norway \\
\hline F5 $7^{\mathrm{d}}$ & C. lumpus & Iceland \\
\hline M. japonica JCM 10249 & Seawater & Japan \\
\hline M. marina NCIMB 1144 & Seawater & $?$ \\
\hline \multicolumn{3}{|c|}{ 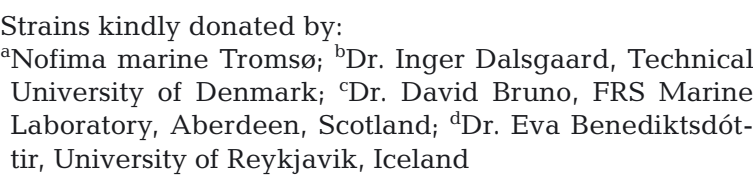 } \\
\hline
\end{tabular}

tion of colony morphology and haemolysis on BAS; Gram stain; motility; oxidative/fermentative production of acid from glucose; production of gas from glucose; sensitivity to vibriostat $(\mathrm{O} / 129)$; production of catalase; production of arginine dihydrolase, lysine- and ornithine decarboxylases (Møller 1955); production of gelatinase; pro- 
duction of acid from cellobiose, mannose and trehalose; and growth at $4^{\circ} \mathrm{C}$ and $30^{\circ} \mathrm{C}$. All test media with the exception of those used to determine temperature range were incubated at $15^{\circ} \mathrm{C}$. Otherwise, biochemical characterisation was carried out using standard methodology. Arginine dihydrolase and lysine- and ornithine decarboxylase tests were observed for $7 \mathrm{~d}$.

Pulsed field gel electrophoresis (PFGE). Bacterial isolates were grown on blood agar supplemented with $2 \% \mathrm{NaCl}$ for $2 \mathrm{~d}$ at $15^{\circ} \mathrm{C}$. The gel plugs were made as described by Martinez-Urtaza et al. (2004), with the following modification: the cell concentration was decided using a spectrophotometer, and the optical density was adjusted to 1.16 to 1.39 (at $610 \mathrm{~nm}$ ). A small (approximately $4 \times 5 \mathrm{~mm}$ ) portion of the plug was first incubated in NotI buffer (New England Biolabs) for $1 \mathrm{~h}$ at $37^{\circ} \mathrm{C}$. The buffer was then replaced by fresh buffer containing $20 \mathrm{U}$ Not I and incubated for $3 \mathrm{~h}$ at $37^{\circ} \mathrm{C}$. Restriction fragments were subjected to electrophoresis in $1 \%$ agarose (SeaKem Gold Agarose, Cambrex) gels in 0.5× Tris-Borate-EDTA (TBE) buffer using a CHEF-DR III system (Bio-Rad). Salmonella Braenderup H9812 digested with $20 \mathrm{U} \mathrm{XbaI} \mathrm{(New} \mathrm{England} \mathrm{Biolabs)} \mathrm{at} 37^{\circ} \mathrm{C}$ for $3 \mathrm{~h}$ was used as a marker. Running conditions were $6 \mathrm{~V} \mathrm{~cm}^{-1}$ at a field angle of $120^{\circ}$, at $12^{\circ} \mathrm{C}$ for $22 \mathrm{~h}$. Pulse times were increased step-wise as follows: $5 \mathrm{~s}$ for $4 \mathrm{~h}$, $9 \mathrm{~s}$ for $4 \mathrm{~h}, 12 \mathrm{~s}$ for $4.5 \mathrm{~h}, 20 \mathrm{~s}$ for $4.5 \mathrm{~h}, 25 \mathrm{~s}$ for $2.5 \mathrm{~h}$ and $30 \mathrm{~s}$ for $2.5 \mathrm{~h}$. Following electrophoresis the gels were stained in ethidium bromide $\left(2 \mu \mathrm{g} \mathrm{ml}^{-1}\right)$ for $20 \mathrm{~min}$, destained in water for $15 \mathrm{~min}$ and photographed under UV-transillumination (GeneGenius, Syngene). PFGE results were analyzed using the Bionumerics Software Package (Bio-Maths) and dendrograms constructed using the Dice Coefficient of similarity and cluster analysis with the unweighted pair-group method with arithmetic averages (UPGMA).

Plasmid profiling. Cultures were grown (with shaking) at $15^{\circ} \mathrm{C}$ in Lysogeny Broth (LB) (Bertani 1951) supplemented with $2 \% \mathrm{NaCl}$ to mid-logarithmic phase, and cells collected by centrifugation at $4{ }^{\circ} \mathrm{C}(10 \mathrm{~min}$, $4000 \times g$ ). Plasmid isolation was performed using the Qiaprep Spin Miniprep kit (Qiagen) according to the manufacturer's instructions. Plasmids were separated by gel electrophoresis using $1 \%$ agarose gels at $90 \mathrm{~V}$ for $1 \mathrm{~h}$ at room temperature. Supercoiled DNA ladder (Invitrogen) was used as a molecular marker.

Sequencing of 16S rRNA and gyrB genes. The genes studied were amplified and sequenced using the primers described in Table 2. Although the $16 \mathrm{~S}$ analysis was limited to Moritella viscosa isolated in Norway, isolates originating from salmon, rainbow trout and cod were included. The obtained 16S rRNA sequences were submitted to Genbank under accession numbers GU138619-GU138626.

Primers for amplification of $g y r B$ sequences were designed using a draft genome sequence of the type strain (NCIMB 13548) as reference (access to this sequence is available via the corresponding author). A fragment of the gyrB gene, of approximately 1670 to $2500 \mathrm{bp}$, was amplified and sequenced in isolates 2033, 3999, 4179, 5450, 5507 and 5683, while a fragment of approximately $1000 \mathrm{bp}$ was sequenced in the remaining isolates. Internal primers for sequencing were designed using either the draft sequence or by primer walking in isolates with significant sequence variation. The obtained gyrB sequences were submitted to Genbank under accession numbers GU124771-GU124812.

DNA sequencing was performed using DYEnamic ${ }^{\mathrm{TM}} \mathrm{ET}$ dye terminator chemistry (Amersham Biosciences) and a MEGABACE $1000^{\mathrm{TM}}$ capillary sequencer (Amersham). Sequences were compiled using either the Sequencher program (Gene Codes Corp, Genetics Computer Group [GCG], Oxford Molecular) or Vector NTi (Invitrogen), and their identity confirmed using BLAST search analysis (Altschul et al. 1997). Obtained sequences and sequences accessed from Genbank were aligned in ClustalX (Thompson et al. 1997) prior to Neighbour-joining (Kimura 2-parameter)

Table 2. Primer oligonucleotides used for PCR amplification and sequencing

\begin{tabular}{|c|c|c|c|}
\hline Name & Gene & Sequence & Reference \\
\hline FD1 & 16S $r R N A$ & 5'-AGA GTT TGA TCC TGG CTC AG-3' & Weisburg et al. (1991) \\
\hline RP2 & $16 \mathrm{~S} r R N A$ & 5'-ACG GCT ACC TTG TTA CGA CTT-3' & Weisburg et al. (1991) \\
\hline MvgyrBF & gyrB & 5'-TGG CGC AGT ATC TGA TTG AG-3' & This study \\
\hline MvgyrBR & gyrB & 5'-GCA ACC GCT TAA TCA TAG CC-3' & This study \\
\hline MvgyrB 251F & gyrB & 5'-ATG AAG AAG AGG GTG TTT-3' & This study \\
\hline $751 \mathrm{~F}$ & gyrB & 5'-GGA ATT ACT GTT GAA GTT-3' & This study \\
\hline $2001 \mathrm{~F}$ & gyrB & 5'-ATC TAT CCG CCA ACA TGG-3' & This study \\
\hline $1251 \mathrm{~F}$ & gyr $B$ & 5'-TCC TGC ACT TTC TGA ACT-3' & This study \\
\hline $1759 \mathrm{~F}$ & gyrB & 5'-GTA AAT GGT TAT CGT AAG-3' & This study \\
\hline 2155R & gyrB & 5'-AAT TAG TTA CTT CAC GAC-3' & This study \\
\hline 1665R & gyrB & 5'-TGT TAA GTC TGC ATC ATC-3' & This study \\
\hline 1149R & gyrB & 5'-CGC ACG TGA TGC ATC GAT-3' & This study \\
\hline $665 \mathrm{R}$ & gyrB & 5'-ATA CCA CCT TCA TAA ACG-3' & This study \\
\hline $165 \mathrm{R}$ & gyr $B$ & 5'-ATG ACC CGC TAA TGC TTC-3' & This study \\
\hline
\end{tabular}


analysis in PAUP* 4.0 (Swofford 2002). Ambiguous bases were excluded from the analysis. Bootstrap confidence values were obtained with 1000 re-samplings.

Western blotting. Samples were prepared for sodium dodecyl sulphate-polyacrylamide gel electrophoresis (SDS-PAGE) as described by Lunder et al. (2000), except that samples in the present study were not treated with proteinase $\mathrm{K}$ and were only heated at $37^{\circ} \mathrm{C}$ for $10 \mathrm{~min}$. Antigens were separated by SDSPAGE using the Amersham Pharmacia Multiphor II Flatbed Electrophoresis System and 8 to $18 \%$ precast gradient gels (ExcelGel SDS Gradient, 80-1255-53, Amersham Pharmacia) and subsequently transferred to nitrocellulose membranes (162-0234, Bio-Rad) using the method of Olsen \& Wiker (1998). Precision Protein Standards (10 to $250 \mathrm{kDa}$ ) (161-0362, Bio-Rad) were used as molecular weight (MW) markers. Immunostaining of transferred Moritella viscosa antigens was performed by the following procedure: (1) blocking with $5 \%$ skimmed milk in phosphate-buffered saline (PBS) with 0.1\% Tween-20 (PBS/Tween); (2) incubation with primary rabbit anti- $M$. viscosa antiserum in PBS/Tween; (3) incubation with peroxidase conjugated donkey anti-rabbit (NA934, Amersham) in PBS/ Tween; (4) colour development using 3,3-diaminobenzidine tetra-hydrochloride (D5637, Sigma) in $0.1 \mathrm{M}$ $\mathrm{NaCH}_{3} \mathrm{CO}_{2}, 0.005 \% \mathrm{H}_{2} \mathrm{O}_{2}$ (pH 4.0). All steps were carried out at room temperature and were separated by 3 washes in PBS/Tween. Three different rabbit anti- $M$. viscosa antisera were employed as primary antiserum: $\alpha$-Vvi-1 (1:5000) (kindly provided by M. Pallapothu, Novartis Animal Health Canada Inc.; raised against $M$. viscosa isolated from Norwegian Atlantic salmon), $\alpha$ 5450 (1:1000) (raised against M. viscosa 5450 isolated from Norwegian rainbow trout, National Veterinary Institute) and $\alpha$-NCIMB 13548 (1:500) (raised against $M$. viscosa NCIMB 13548, the species type strain isolated from Norwegian Atlantic salmon, National Veterinary Institute).

Histopathological studies. Histological samples were taken during 2 cases of ulcer development in rainbow trout during January and March of 2007. Gills, heart, liver, kidney, spleen, pancreatic tissue and skeletal musculature were sampled. The samples were fixed in $4 \%$ neutral buffered formalin, embedded in paraffin wax and routinely processed. The sections were stained by haematoxylin and eosin (H\&E).

\section{RESULTS}

\section{Histopathology}

The observed pathological changes were in accordance with previous descriptions of infection with
Moritella viscosa (Lunder et al. 1995, Bruno et al. 1998). The histopathology of skin ulcers revealed subepidermal oedema, dermal inflammation, haemorrhage and inflammation in subcutis and underlying red muscle and some necrosis of white muscle fibers. Liver tissues demonstrated moderate to marked focal congestion with dilated, blood-filled sinusoids.

An increased number of circulating neutrophils was observed. No striking differences in pathological changes were observed on comparison of disease caused by the typical or variant cluster in Atlantic salmon and rainbow trout respectively.

\section{Phenotypical characterisation}

With the exception of non-Moritella viscosa species, all tested isolates produced viscous haemolytic colonies on BAS. Slight differences in colony pigmentation were perceived, with isolates belonging to the subsequently denoted typical strain appearing to be greyer in colour than the variant isolates which were considered to have a slight yellowish/orange pigmentation on BAS. All isolates were motile, short, Gram-negative pleomorphic rods which produced acid from glucose under anaerobic conditions, did not produce gas from glucose, were slightly sensitive to vibriostat (O/129), produced catalase and gelatinase, but did not produce acid from cellobiose or trehalose. All isolates grew well at $4^{\circ} \mathrm{C}$ but not at $30^{\circ} \mathrm{C}$. Degree and type of haemolysis and production of acid from mannose were identified as variable in the M. viscosa isolates studied. The most apparent difference was that relating to the degree of haemolysis observed on plating on BAS (Fig. 1). The isolates originating from salmon farmed in Norway, Scotland and the Faroe Islands produced a relatively weak beta-haemolysis, while isolates from rainbow trout and salmon farmed in Iceland produced a visibly stronger haemolytic zone over a larger area around the colony. More extensive haemolysis, i.e. larger diffusion zones, were also observed in 2 Canadian isolates, 2 Icelandic isolates and 1 isolate from cod. Acid production from mannose (Fig. 1) appeared to be a somewhat quantitative trait rather than absolute. With the exception of 3 isolates which displayed very weak acidification of the media, all Norwegian, Scottish and Faroe Atlantic salmon isolates were clearly negative, while Canadian salmon isolates, 4 of 5 Icelandic salmon isolates and $64 \%$ of rainbow trout isolates were clearly positive. While slight acidification was apparent in one isolate from cod, the remaining 4 isolates tested were clearly negative. Very weak production of lysine decarboxylase (Fig. 1) was identified in a larger proportion $(62.5 \%)$ of the Norwegian, Scottish and Faroe Atlantic salmon isolates compared to the remaining isolates $(20.8 \%)$. 


\begin{tabular}{|c|c|c|c|c|c|c|}
\hline & & & & Haemolysis & $\begin{array}{l}\text { Prod. of acid } \\
\text { from mannose }\end{array}$ & $\begin{array}{l}\text { Prod. of lysine- } \\
\text { decarboxylase }\end{array}$ \\
\hline & K58 & S. salar & Iceland & +++ & + & - \\
\hline & K2 & S. salar & Iceland & +++ & + & - \\
\hline & F153 & S. salar & Iceland & +++ & + & + \\
\hline & Vvi-11 & S.salar & Canada & $+++^{\#}$ & + & - \\
\hline & Vvi-7 & S. salar & Canada & $+++^{\#}$ & + & - \\
\hline & NVI 4917 & O. mykiss & Norway & +++ & + & - \\
\hline & NVI 4692 & O. mykiss & Norway & +++ & - & - \\
\hline & NVI 4547 & G. morhua & Norway & +++ & $(-)$ & - \\
\hline & ${ }^{80}$ NVI 5204 & G. morhua & Norway & +++ & - & - \\
\hline & NVI 6185 & O. mykiss & Norway & +++ & + & + \\
\hline & NVI 3968 & O. mykiss & Norway & +++ & + & - \\
\hline & NVI 4958 & O. mykiss & Norway & +++ & + & - \\
\hline & $100 \mid$ NVI 5450 & O. mykiss & Norway & +++ & + & + \\
\hline & NVI 5683 & O. mykiss & Norway & +++ & + & - \\
\hline & NVI 5168 & O. mykiss & Norway & +++ & + & - \\
\hline & ${ }_{82}$ NVI 5507 & G. morhua & Norway & +++ & - & - \\
\hline & F57 & C. lumpus & Iceland & +++ & $(-)$ & - \\
\hline & NVI 5471 & G. morhua & Norway & +++ & - & - \\
\hline 95 & K56 & S. salar & Iceland & $++^{\#}$ & - & - \\
\hline & NVI 4731 & S. salar & Norway & $++^{\#}$ & + & - \\
\hline & 60 F162/01 & O. mykiss & Iceland & +++ & - & - \\
\hline 52 & NVI 6184 & O. mykiss & Norway & +++ & - & + \\
\hline & $\left.69\right|^{\text {NVI } 5433}$ & S. salar & Norway & +++ & - & - \\
\hline & NVI 4869 & O. mykiss & Norway & +++ & - & + \\
\hline & L Moritella ja & aponica JCM 1 & 249 & + & - & + \\
\hline & Moritella $m$ & narina NCIMB & 144 & + & + & - \\
\hline & (990217-1/1A ) & & Faroe & + & - & + \\
\hline & $990129-1 / 3 B$ & & Islands & + & - & + \\
\hline & MT 2858 & & Scotland & + & - & + \\
\hline & MT 2528 & & & + & - & - \\
\hline & NVI 4679 & & & + & - & + \\
\hline & NVI 6216 & & & + & $(-)$ & - \\
\hline & NVI 1527 & & & + & - & + \\
\hline & NVI 6562 & S. salar & & + & $(-)$ & - \\
\hline & NVI 3999 & & & + & - & + \\
\hline & NVI 2989 & & Norway & + & $(-)$ & - \\
\hline | & NVI 5443 & & Torvady & + & - & + \\
\hline jyo| & LFI 5006 & & & + & - & + \\
\hline & NVI 4397 & & & + & - & + \\
\hline & NVI 4179 & & & + & - & - \\
\hline & NCIMB 13584 & & & + & - & + \\
\hline & NVI 5482 & G. morhua & & $+\#$ & - & - \\
\hline
\end{tabular}

Fig. 1. Neighbour-joining analysis of the gyrB gene (926 bp) of Moritella marina, M. japonica, Moritella PE36 and M. viscosa isolated from various fish species from different geographical areas. Bootstrap values are percent of 1000 replicates. For aesthetic reasons some bootstrap values between closely related branches have been omitted. Haemolytic properties and the ability of each strain to produce acid from mannose and lysine decarboxylase are also included. Parentheses indicate slight acidification of the media. Haemolysis was evaluated as weak $(+)$; moderate $(++)$; or strong $(+++)$. \# indicates a relatively larger zone of haemolysin diffusion. Fish species are Gadus morhua, Salmo salar, Oncorhynchus mykiss, Cyclopterus lumpus 


\section{Plasmid profiling}

The isolates examined fell into 2 clearly separated groups (Fig. 2). One group comprised isolates from salmon in Norway, Scotland and the Faroe Islands in which each isolate produced a clear plasmid profile of 4 to 7 bands, many of which were common to several or all isolates. The second group comprised isolates from various fish species in Canada, Iceland and Norway which produced plasmid profiles consisting of between 0 and 4 bands, with the majority of isolates displaying no obvious plasmid bands.

\section{PFGE analysis}

Moritella viscosa isolates formed 2 distinct clades (Fig. 3), consistent with the division indicated by phenotypical differences and plasmid profiling. One clade comprises closely related isolates, originating exclusively from Atlantic salmon in Norway, Scotland and the Faroe Islands, along with a single less related isolate from Norwegian cod. The second distinct cluster consists of rather less related isolates from salmon, rainbow trout and lumpsucker from Iceland, Norwegian rainbow trout and Atlantic salmon from Canada. $M$. japonica and M. marina did not cluster with either of the $M$. viscosa groups.

\section{S rRNA analysis}

Exclusion of missing and/or ambiguous characters resulted in analysis of 1332 bases. While 16S rRNA analysis (Fig. 4) clearly distinguished the various Moritella species, identical sequences were obtained from all isolates of Norwegian $M$. viscosa studied, irrespective of host species.

\section{gyrB analysis}

Removal of gaps and ambiguous bases resulted in analysis of a $926 \mathrm{bp}$ sequence common to all sequenced isolates. A total of 40 Moritella viscosa isolates from different fish and various geographic origins as well as M. marina NCIMB 1144, M. japonica JCM 10249 and PE 36 (Acc. Nr. NZ ABCQ01000076) were analysed. Neighbour-joining analysis of gyrB (Fig. 1) clearly separated the various species. $M$. viscosa isolates were also split into 2 relatively deeply divided clusters, consistent with the division identified by phenotypical testing, plasmid profiling and PFGE. One cluster consisted, with the exception of a highly similar but not identical isolate from cod in Norway, of identical isolates (including the type strain), originating from Atlantic salmon farmed in Norway, Scotland and the Faroe Islands. The second cluster comprised a closely related but slightly

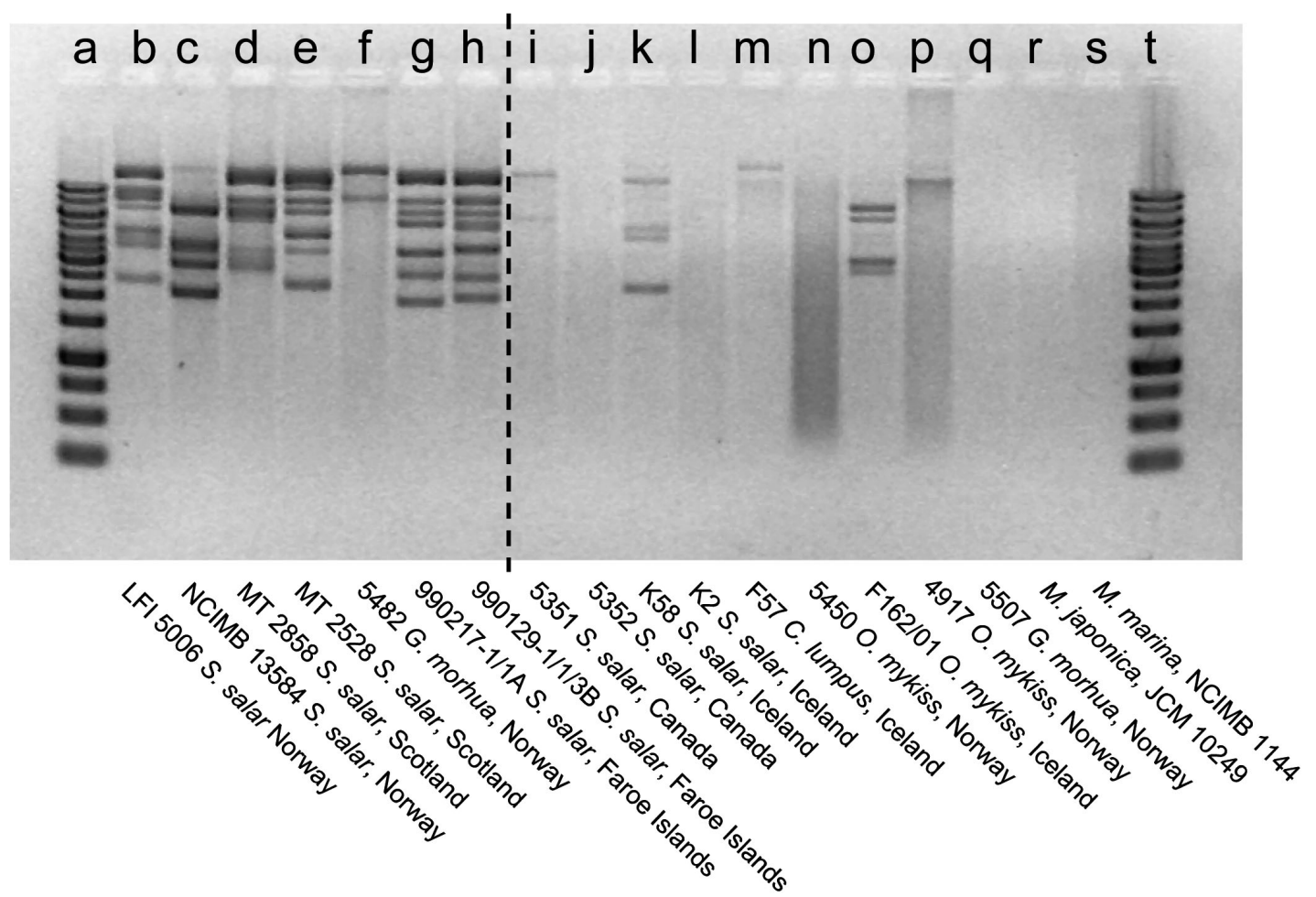

Fig. 2. Plasmid profiles of Moritella viscosa isolated from various species of fish from different geographical areas. Lanes (a) and $(\mathrm{t})$ : molecular weight markers. The dashed line separates the 2 gyrB clusters 


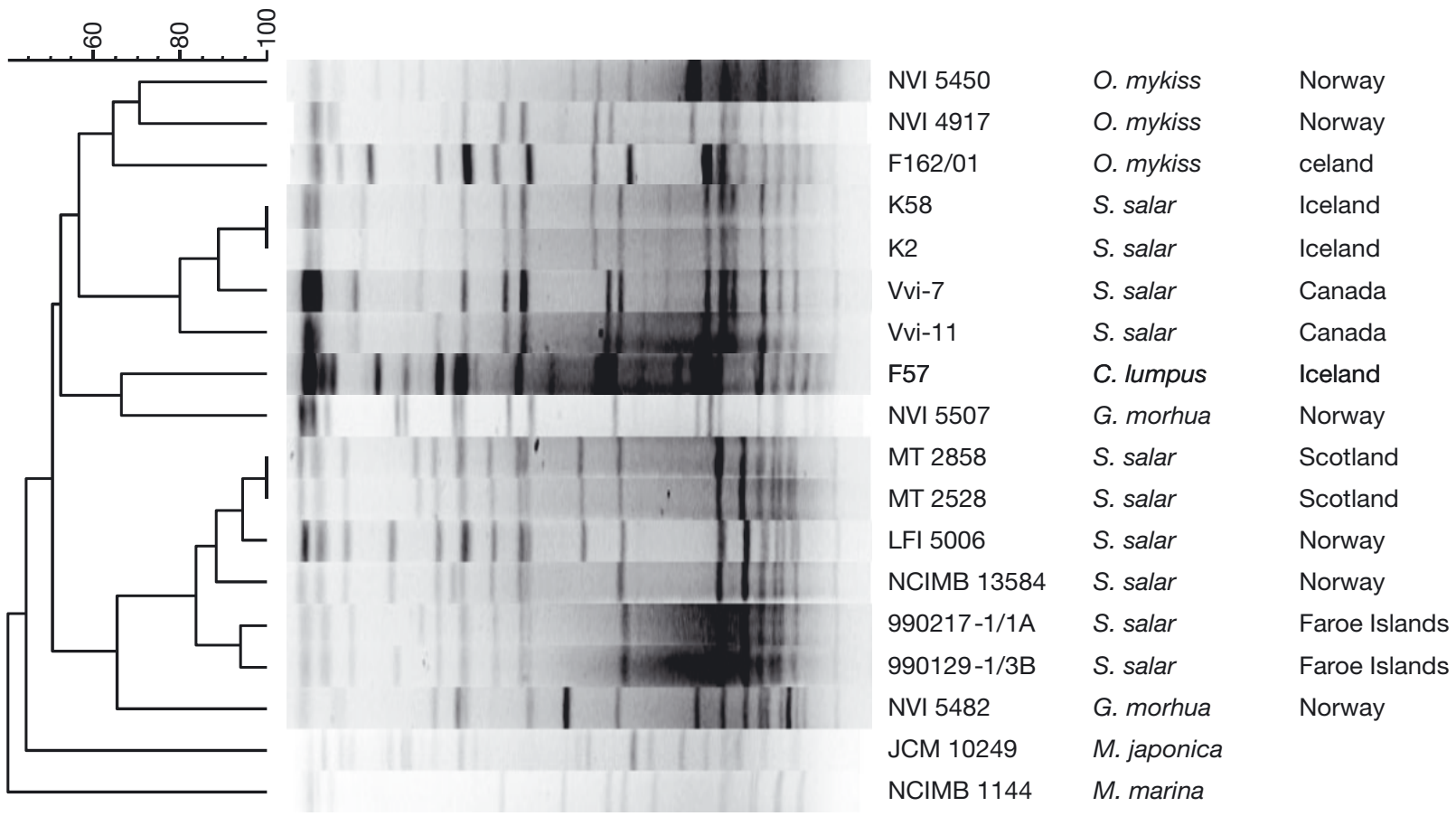

Fig. 3. Pulsed field gel electrophoresis analysis of Moritella viscosa isolated from various species of fish from different geographical areas. Isolate designation, fish species and country of isolation are shown

more heterogeneous group of isolates from various fish species in Norway, Iceland and Canada. M. japonica and $M$. marina were placed between the $2 M$. viscosa clades. No isolates with the type strain $g y r B$ sequence were identified in species other than salmon, although the single cod isolate which was identified as closely related to the type strain clade by PFGE is also very closely related by gyrB analysis.

\section{Western blot analysis}

By Western blotting, all 3 antisera were able to clearly distinguish the various Moritella species (Fig. 5). Although $M$. viscosa showed band patterns that were predominantly similar, some noteworthy differences were also identified (Table 3 ). Using the $\alpha-5450$ sera raised against $M$. viscosa from Norwegian rainbow trout, isolates from Norwegian rainbow trout showed a double band at 200 to $250 \mathrm{kDa}$, of which the 200 band was the dominant. This contrasted with all salmon isolates from Iceland/Canada and most salmon isolates from Norway/Scotland/Faroes in which the $250 \mathrm{kDa}$ band dominated. Notably, the Icelandic rainbow trout isolates had no detectable $\sim 200 \mathrm{kDa}$ band. In cod isolates from Norway, lumpsucker from Iceland and one salmon isolate from Scotland, both protein bands were almost equal in strength. Western blotting using $\alpha$-NCIMB 13548 (type strain from Norwegian Atlantic salmon) and $\alpha$-Vvi-1 antisera also suggested antigenic differences between analysed isolates in this MW region (Table 3). Further, the $\alpha$-Vvi-1 was able to distinguish between isolates by showing differential band patterns at both $110 \mathrm{kDa}$ and 130 to $135 \mathrm{kDa}$ (Table 3). For all employed antisera, the lumpsucker isolate was distinguished by a band at $\sim 80 \mathrm{kDa}$ which in all other bands appeared to be 5 to $10 \mathrm{kDa}$ heavier. In summary, despite relative small differences, the Western blot analysis was able to separate the salmonid $M$. viscosa isolates into 4 antigenically distinct groups: Norwegian rainbow trout, Icelandic rainbow trout, Icelandic/Canadian salmon and finally Norwegian/Scottish/Faroese salmon.

\section{DISCUSSION}

The genus Moritella currently consists of 7 validly described species (www.bacterio.cict.fr), most of which are associated with deep marine environments, and contains $M$. viscosa, an established cause of winterulcer in fish farmed in countries bordering the northern Atlantic Ocean.

Although antigenic heterogeneity has been previously identified within Moritella viscosa (Benediktsdóttir et al. 2000, Heidarsdóttir et al. 2008), little has been performed in the way of phenotypic and genetic comparison of this bacterium since the original species descriptions (Benediktsdóttir et al. 2000, Lunder et al. 2000). Until the present study, only $2 \mathrm{M}$. viscosa $16 \mathrm{~S}$ rRNA sequences (Lunder et al. 2000, Colquhoun et al. 


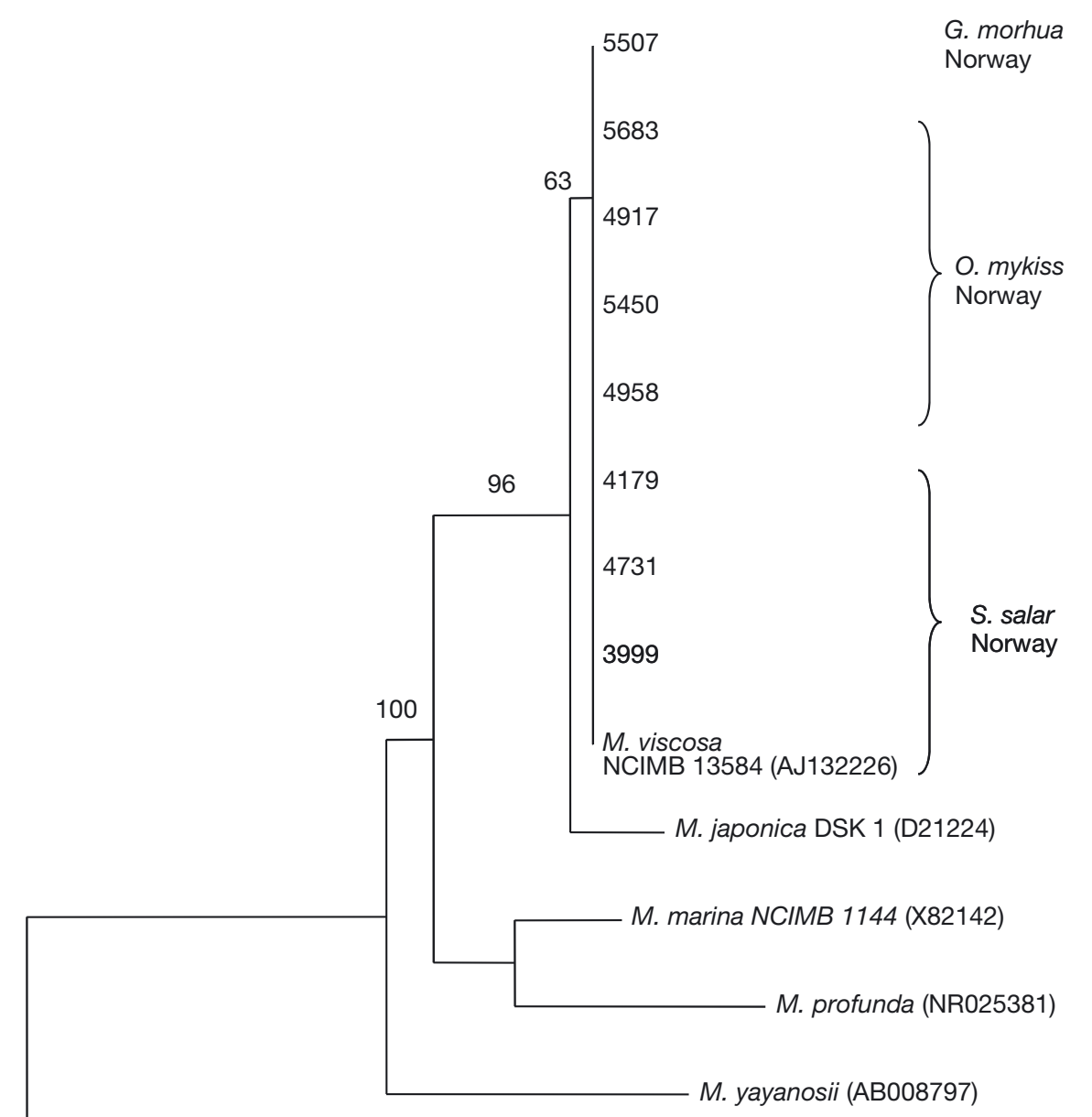

- Moritella PE36 (DQ027053)

0.001 substitutions site ${ }^{-1}$
Fig. 4. Neighbour-joining analysis of the 16S rRNA gene (1332 bp) from Moritella viscosa isolated from various fish species in Norway and other Moritella spp. Bootstrap values are percent of 1000 replicates
2004), both from Norwegian farmed fish, were available in Genbank (www.ncbi.nlm.nih.gov/), and intraspecies phenotypical differences were undocumented.

The current study, which identified a previously unrecognised degree of phenotypical and genetic differences within the species Moritella viscosa, was instigated following a series of outbreaks of winter-ulcer, characterised by high levels of mortality, in farmed rainbow trout in Norway during 2005 and 2006. Bacterial isolates from these outbreaks, whilst phenotypically consistent with $M$. viscosa, differed in some respects to those normally isolated from Atlantic salmon in this country.

Clinically, the disease caused by the variant strain in rainbow trout in the studied case did not appear to differ markedly from that observed in winter-ulcer in Atlantic salmon caused by the typical strain. Although the material examined histologically in the present study was relatively modest, no evidence for significant differences in transmission or pathology exists either from the present study or previous studies related to Koch's postulates (Lunder et al. 1995, Bruno et al. 1998).

The study, which included isolates from all the major North Atlantic salmonid producing countries, found Moritella viscosa, M. marina and $M$. japonica to be phenotypically very similar, using standard diagnostic methodology. Whilst clearly genetically separated by both 16S rRNA and gyrB sequence analysis, M. japonica and $M$. marina could be distinguished phenotypically from $M$. viscosa only by their low colony viscosity. $M$. viscosa isolates were found to form a uniform cluster following analysis of 16S rRNA sequences, but formed 2 clearly separate genotypes following $g y r B$ sequence analysis. Phenotypically the 2 genotypes of M. viscosa are highly similar, only clearly differing in 


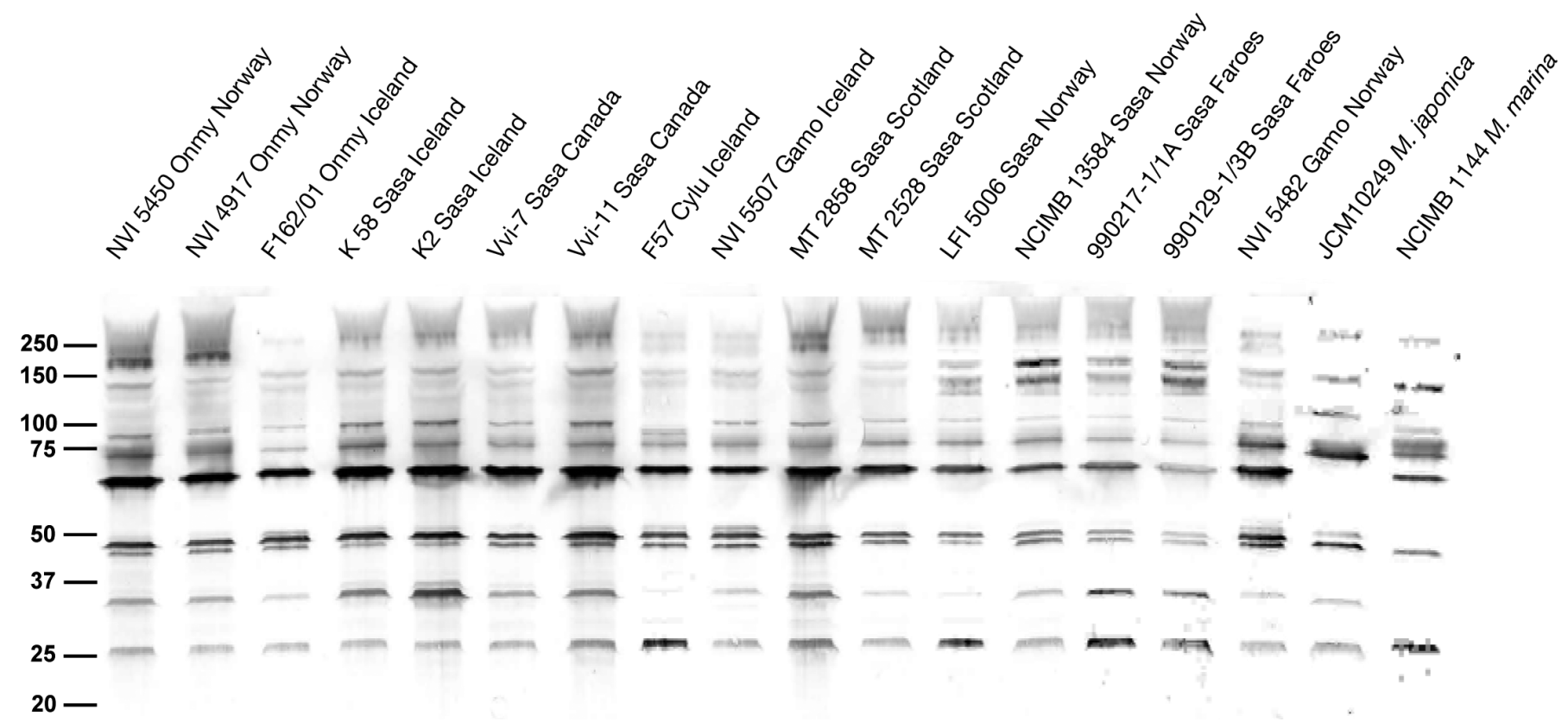

Fig. 5. Western Blot analysis of Moritella species and M. viscosa isolates using the $\alpha-5450$ antiserum as primary antibody. Onmy, Oncorhynchus mykiss; Sasa, Salmo salar; Gamo, Gadus morhua; Cylu, Cyclopterus lumpus. Lane 1: molecular weight standard in $\mathrm{kDa}$

Table 3. Summary of selected Western blotting data that distinguish Moritella viscosa strains isolated from rainbow trout and Atlantic salmon. Onmy: rainbow trout; Sasa: salmon; N, Norway; I, Iceland; C, Canada; S, Scotland; F, Faroese. Numbers indicate approximate molecular weight of bands, boldface type indicates strong/dominant band, while dash $(-)$ indicates absence of detectable band. $\alpha$-NCIMB 13548: rabbit antiserum raised against Moritella viscosa NCIMB 13548 (species type strain) isolated from Norwegian Atlantic salmon. $\alpha-5450$ : rabbit antiserum raised against M. viscosa strain 5450 isolated from Norwegian rainbow trout. $\alpha$-Vvi-1: rabbit antiserum raised against $M$. viscosa strain Vvi-1 isolated from Norwegian Atlantic salmon

\begin{tabular}{|c|c|c|c|c|}
\hline Antiserum & Onmy N & Onmy I & Sasa I/C & Sasa N/S/F \\
\hline$\alpha$-NCIMB & 250 & 250 & 250 & 250 \\
\hline 13548 & 200 & - & - & 200 \\
\hline \multirow[t]{2}{*}{$\alpha-5450$} & 250 & 250 & 250 & $250^{\mathrm{a}}$ \\
\hline & 200 & - & 200 & 200 \\
\hline \multirow{5}{*}{$\alpha-V v i-1$} & 250 & 250 & 250 & 250 \\
\hline & 200 & 200 & 200 & 200 \\
\hline & 135 & 135 & 135 & 135 \\
\hline & 130 & 130 & 130 & 130 \\
\hline & 110 & - & 110 & - \\
\hline \multicolumn{5}{|c|}{$\begin{array}{l}\text { an one Scottish salmon strain (MT 2858), the bands were } \\
\text { equally strong }\end{array}$} \\
\hline
\end{tabular}

haemolytic activity. Otherwise, variable test results including acid production from mannose and production of lysine decarboxylase were not absolutely related to genotype although these abilities or lack thereof appeared to be associated with certain genotypes, i.e. the Norwegian salmon cluster consistently failed to produce acid from mannose, while a higher proportion of these isolates produced lysine decarboxylase in our tests.

The division within the species Moritella viscosa illuminated in the current study is supported by all techniques used. The evidence indicates that at the phenotypic and 16S rRNA level, the 2 clusters are closely related. However, the combined evidence from $g y r B$ analysis, plasmid profiling, PFGE and Western blotting would suggest that a relatively longstanding division exists between these 2 sub-populations. Although gyrB has been found to show little or no resolution in some closely related Vibrio species (Thompson et al. 2007), it has been used extensively in phylogenetic studies for this genus (e.g. González-Escalona et al. 2008, Thompson et al. 2009) which is relatively closely related to Moritella. The functional conservation in gyrB in $M$. viscosa is illustrated by the relatively low level of nucleic acid identity (92.5\%) yet high level of amino acid identity (97.7\%) and similarity (98.3\%) maintained between the type strain (NCIMB 13584) and isolate 5450 from rainbow trout. Thus, it can be concluded that most if not all of the nucleic acid substitutions have occurred through random, non-selective mutation rather than horizontal gene transfer, and that a considerable period of time must have elapsed to allow such an accumulation. 
Though the differences revealed by Western blotting were relatively small, they appear to follow the division between strains found by the phenotypical and genetic methods. Isolates from Atlantic salmon thus cluster into a Norwegian/Scottish/Faroese ('Eastern Atlantic') group and an Icelandic/Canadian ('Western Atlantic') group. Isolates from Norwegian rainbow trout are distinct from the 2 Atlantic salmon groups and from the single isolate analysed from Icelandic rainbow trout. In a Western blotting analysis, Heidarsdóttir et al. (2008) identified a strain difference in the MW of a $17 / 19 \mathrm{kDa}$ outer membrane protein that was compatible with the presently observed division. Hence, while a 17/19 kDa protein was shown to be of lower MW in isolates from Norwegian/Scottish Atlantic salmon compared to isolates from Iceland/ Canada, it was absent in an isolate from Icelandic rainbow trout.

Although the results of the present study clearly identify a deep division within the species Moritella viscosa represented by 2 distinct genetic clusters of isolates, it is not immediately clear whether the 2 identified groups of bacteria comprise ecologically distinct populations. The typical strain does not appear to cause disease in rainbow trout in Norway, while the variant strain causes disease only exceptionally in salmon in this country. If the studied strains are representative, the typical strain does not appear to have been isolated from diseased fish in Iceland or Canada, although the low numbers of isolates studied means that its absence from these waters cannot be assumed. It is, however, clear that in Icelandic and Canadian waters the variant strain is capable of causing disease in both salmon and rainbow trout.

Although overshadowed by salmon farming in terms of production (741000 t compared to $86000 \mathrm{t}$; Kjønhaug 2009) in Norway, rainbow trout are farmed in similar or identical areas of the Norwegian coastline as salmon. Retrospective analysis of isolates obtained from rainbow trout in the course of diagnostic work performed by the Norwegian National Veterinary Institute has failed to identify the presence of the typical strain in these cases, while the new variant strain has only exceptionally been identified in farmed Atlantic salmon. The reasons for this are not immediately clear, as isolates of this type appear to be relatively commonly isolated from salmon farmed in Iceland.

It is interesting to note that sea-farming of rainbow trout in Iceland was seriously affected by Moritella viscosa infection prior to the introduction of vaccination (Gudmundsdóttir \& Bjornsdóttir 2007), while the incidence of such disease in this fish species in Norway is historically very low.

In Canada and Iceland the typical strain appears to be absent at least in the studied material, while the 'variant' strain was identified in all fish species studied. It could be argued that the apparent host specificity of the typical strain for Atlantic salmon is in fact the case and that it has not been identified in Iceland and Canada is due to its absence from these waters. That the variant strain is found in Atlantic salmon farmed in Iceland and Canada may correspond to the 'occasional' isolation of this strain in Atlantic salmon in Norway. As winter-ulcer is not a notifiable disease, absolute statistics are not available. However, from experience it appears that Norway has a much higher incidence of winter-ulcer in farmed salmon than Iceland or Canada. This could conceivably be explained by the presence of a strain particularly virulent for Atlantic salmon (i.e. the type strain) in Norwegian waters. The lower incidence of winter-ulcer in Scottish salmon may be related to higher winter water temperatures. It may therefore be speculated that a degree of host specificity may exist at least in the Norwegian/Scottish/Faroe Islands salmon strain of Moritella viscosa.

In the absence of evidence to the contrary, Moritella viscosa has until now, and for the purposes of vaccine production, been considered to be a largely homogeneous species. This presumption, despite the evidence presented by the present study, may be relatively safe as far as the overall susceptible population of fish is concerned. Winter-ulcer is a far more significant disease in Norwegian aquaculture compared to the other salmon farming countries, and Atlantic salmon account for a dominating proportion of the fish raised in this country. Isolates from Atlantic salmon in Norway must therefore account for the overwhelming majority of clinical $M$. viscosa isolates on a worldwide basis. Despite the antigenic differences identified during the present study and by Heidarsdóttir et al. (2008), crossprotection has been reported between Icelandic (presumed variant) and Norwegian (typical) strains (Greger \& Goodrich 1999). The previous assumption of homogeneity may therefore not have been as significant in relation to protection of vaccinated stocks as it otherwise might have been.

In conclusion, it has been established that the species Moritella viscosa can be phenotypically and genetically split into 2 more or less homogeneous strains. It is not yet clear whether these strains are ecologically limited in relation to geographical distribution and host fish species specificity. Further characterisation regarding precise taxonomic placement of the newly identified variant strain is necessary and is currently being performed in our laboratories.

Acknowledgements. This study was funded in part by The Norwegian Research Council (grant number 174241), ScanVacc AS and the National Veterinary Institute. 


\section{LITERATURE CITED}

Altschul SF, Madde TL, Schäffer AA, Zhang J, Miller W, Lipman DJ (1997) Gapped BLAST and PSI-BLAST: a new generation of protein database search programs. Nucleic Acids Res 25:3389-3402

Benediktsdóttir E, Helgason S, Sigurjónsdóttir H (1998) Vibrio spp. isolated from salmonids with shallow skin lesions and reared at low temperature. J Fish Dis 21:19-28

Benediktsdóttir E, Verdonck L, Sproer C, Helgason S, Swings J (2000) Characterization of Vibrio viscosus and Vibrio wodanis isolated at different geographical locations: a proposal for reclassification of Vibrio viscosus as Moritella viscosa comb. nov. Int J Syst Evol Microbiol 50: 479-488

Bertani G (1951) Studies on lysogenesis. I. The mode of phage liberation by lysogenic Escherichia coli. J Bacteriol 62: 293-300

Björnsdóttir B, Gudmundsdóttir S, Bambir SH, Magnadóttir B, Gudmundsdóttir BK (2004) Experimental infection of turbot, Scophthalmus maximus (L.), by Moritella viscosa, vaccination effort and vaccine-induced side-effects. J Fish Dis 27:645-655

Bruno DW, Griffiths J, Petrie J, Hastings TS (1998) Vibrio viscosus in farmed Atlantic salmon Salmo salar in Scotland: field and experimental observations. Dis Aquat Org 34: 161-166

Colquhoun DJ, Hovland $\mathrm{H}$, Hellberg $\mathrm{H}$, Haug T, Nilsen $\mathrm{H}$ (2004) Moritella viscosa isolated from farmed Atlantic cod (Gadus morhua). Bull Eur Assoc Fish Pathol 24:109-114

González-Escalona N, Martinez-Urtaza J, Romero J, Espejo RT, Jaykus LA, DePaola A (2008) Determination of molecular phylogenetics of Vibrio parahaemolyticus strains by multi-locus sequence typing. J Bacteriol 190:2831-2840

Greger E, Goodrich T (1999) Vaccine development for winter ulcer disease, Vibrio viscosus, in Atlantic salmon, Salmo salar L. J Fish Dis 22:193-199

Gudmundsdóttir BK, Björnsdóttir B, Gudmundsdóttir S, Bambir SH (2006) A comparative study of susceptibility and induced pathology of cod, Gadus morhua (L.), and halibut, Hippoglossus hippoglossus (L.), following experimental infection with Moritella viscosa. J Fish Dis 29:481-487

Gudmundsdóttir BK, Björnsdóttir B (2007) Vaccination against atypical furunculosis and winter ulcer disease of fish. Vaccine 25:5512-5523

Heidarsdóttir KJ, Gravningen K, Benediktsdóttir E (2008) Antigen profiles of the fish pathogen Moritella viscosa and protection in fish. J Appl Microbiol 104:944-951

Kjønhaug AF (2009) Production of salmon and rainbow trout 2008. The Annual Coastal Zone and Aquaculture Review 2009. Report. Institute for Marine Research, Bergen, Nor-

Editorial responsibility: David Bruno,

Aberdeen, UK way (in Norwegian)

Lunder T (1992) 'Winter ulcer' in Atlantic salmon. A study of pathological changes, transmissibility and bacterial isolates. PhD thesis, Norwegian School of Veterinary Science, Oslo

- Lunder T, Evensen O, Holstad G, Hastein T (1995) Winter ulcer in the Atlantic salmon Salmo salar-Pathological and bacteriological investigations and transmission experiments. Dis Aquat Org 23:39-49

Lunder T, Sørum H, Holstad G, Steigerwalt AG, Mowinckel P, Brenner DJ (2000) Phenotypic and genotypic characterization of Vibrio viscosus sp. nov. and Vibrio wodanis sp. nov. isolated from Atlantic salmon (Salmo salar) with 'winter ulcer'. Int J Syst Evol Microbiol 50:427-450

Martinez-Urtaza J, Lozano-Leon A, DePaola A, Ishibashi M, Shimada K, Nishibuchi M, Liebana E (2004) Characterization of pathogenic Vibrio parahaemolyticus isolates from clinical sources in Spain and comparison with Asian and North American pandemic isolates. J Clin Microbiol 42: $4672-4678$

Møller V (1955) Simplified tests for some amino acid decarboxylases and for the arginine dihydrolase system. Acta Pathol Microbiol Scand 36:158-172

Olsen I, Wiker HG (1998) Diffusion blotting for rapid production of multiple identical imprints from sodium dodecyl sulfate polyacrylamide gel electrophoresis on a solid support. J Immunol Methods 220:77-84

Swofford DL (2002) PAUP*. Phylogenetic analysis using par-

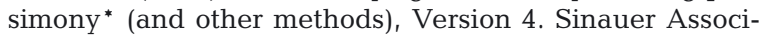
ates, Sunderland, MA

Thompson JD, Gibson TJ, Plewniak F, Jeanmougin F, Higgins DG (1997) The ClustalX windows interface: flexible strategies for multiple sequence alignment aided by quality analysis tools. Nucleic Acids Res 25:4876-4882

Thompson CC, Vicente ACP, Souza RC, Vasconcelos ATR, and others (2009) Genomic taxonomy of vibrios. BMC Evol Biol 9:258

Thompson FL, Gomez-Gil B, Vasconcelos ATR, Sawabe T (2007) Multilocus sequence analysis reveals that Vibrio harveyi and V. campbellii are distinct species. Appl Environ Microbiol 73:4279-4285

Weisburg WG, Barns SM, Pelletier DA, Lane DJ (1991) 16S ribosomal DNA amplification for phylogenetic study. J Bacteriol 173:697-703

Whitman KA, Backman S, Benediktsdóttir E, Coles M, Johnson G (2000) Isolation and characterisation of a new Vibrio sp. (Vibrio wodanis) associated with 'Winter ulcer disease' in sea water raised Atlantic salmon (Salmo salar L.) in New Brunswick. In: Hendry CI, McGladdery SE (eds) Aquaculture Association of Canada Special publications no. 4. St. Andrews, NB, Canada, p 115-117

Submitted: May 17, 2010; Accepted: July 29, 2010

Proofs received from author(s): October 13, 2010 